Dead fuel moisture estimation with MSG-SEVIRI data. Retrieval of meteorological data for the calculation of the equilibrium moisture content

Nieto Solana, Hector; Sandholt, Inge; Aguado, Inmaculada; Chuvieco, Emilio

Published in:

Agricultural and Forest Meteorology

DOI:

10.1016/j.agrformet.2010.02.007

Publication date:

2010

Document version

Early version, also known as pre-print

Citation for published version (APA):

Nieto Solana, H., Sandholt, I., Aguado, I., \& Chuvieco, E. (2010). Dead fuel moisture estimation with MSG-

SEVIRI data. Retrieval of meteorological data for the calculation of the equilibrium moisture content. Agricultural and Forest Meteorology, 150(7-8), 861-870. https://doi.org/10.1016/j.agrformet.2010.02.007 


\title{
Dead fuel moisture estimation with MSG-SEVIRI data. Retrieval of meteorological data for the calculation of the equilibrium moisture content
}

\author{
Héctor Nieto ${ }^{\mathrm{a}, \mathrm{b}, *}$, Inmaculada Aguado $^{\mathrm{a}}$, Emilio Chuvieco ${ }^{\mathrm{a}}$, Inge Sandholt ${ }^{\mathrm{b}}$ \\ a Department of Geography, University of Alcalá, Colegios 2, 28801, Alcalá de Henares, Spain \\ ${ }^{\mathrm{b}}$ Department of Geography and Geology, University of Copenhagen, Øster Volgade 10, 1350, Copenhagen K, Denmark
}

\section{A R T I C L E I N F O}

\section{Article history:}

Received 26 October 2009

Received in revised form 4 February 2010

Accepted 12 February 2010

\section{Keywords:}

Remote sensing

Equilibrium moisture content

Air temperature

Relative humidity

MSG-SEVIRI

Thermal infrared

Precipitable water

\begin{abstract}
A B S T R A C T
In this study we propose to use remote sensing data to estimate hourly meteorological data and then assess the moisture content of dead fuels. Three different models to estimate the equilibrium moisture content (EMC) were applied together with remotely sensed retrieved air temperature and relative humidity. The input data were acquired by the Spinning Enhanced Visible and Infrared Imager (SEVIRI) sensor, on board the Meteosat Second Generation (MSG) satellite, from which air temperature and relative humidity were estimated every $15 \mathrm{~min}$. Air temperature estimations are based on the Temperature-Vegetation Index (TVX) algorithm. This algorithm exploits the inverse linear relationship between the land surface temperature and the vegetation fractional cover. This relationship was evaluated in a spatial window where the meteorological forcing is assumed to be constant. To estimate the vapour pressure, a linear relationship between precipitable water content and vapour pressure has been derived. Precipitable water content was estimated with the thermal infrared bands of SEVIRI using a split-window algorithm and data from ground meteorological stations in Spain during the year 2005 were used to calibrate and validate the vapour pressure models. Finally air temperature and vapour pressure were combined to calculate the EMC for dead fuels and the transfer of errors of these estimates have been assessed with ground meteorological data for three different EMC models. Promising results were obtained, with mean absolute errors ranging from $1.9 \%$ to $2.7 \%$ of moisture content depending on the applied EMC model, but the remote sensed EMC tends to underestimate the EMC from ground data. Improvements in air temperature and vapour pressure estimations would lead to a better agreement between the observed and the predicted values.
\end{abstract}

(c) 2010 Elsevier B.V. All rights reserved.

\section{Introduction}

Most fire danger assessment systems take into account the fuel moisture content (FMC) of dead fuels, since moisture is closely related to fire ignition and propagation potential (Bradshaw and Deeming, 1983). Laboratory studies have shown high correlations between FMC and the ignition delay (Dimitrakopoulos and Papaioannou, 2001), while many studies have identified close links between FMC and both fire rate of spread and fire intensity (Rothermel, 1972). In the case of surface fires, the fire front propagates through the forest floor and thus the moisture of dead fuels is critical in the rate of spread (Aguado et al., 2007; Viney, 1991).

Unlike live vegetation, which can regulate water losses through stomatal closure and water uptake by roots, moisture in dead fuels is subject to sorption, precipitation and latent heat processes (Ruiz

\footnotetext{
* Corresponding author. Tel.: +45 3532 2500; fax: +45 35322501.

E-mail addresses: hn@geo.ku.dk (H. Nieto),inmaculada.aguado@uah.es (I. Aguado), emilio.chuvieco@uah.es (E. Chuvieco), is@geo.ku.dk (I. Sandholt).
}

Gonzalez et al., 2009; Viney and Catchpole, 1991). Dead fuels tend to gain or lose moisture until an equilibrium with the surrounding atmosphere is achieved. This steady moisture content is called equilibrium moisture content (EMC) and is governed by meteorological factors, fuel type, and hysteresis (Catchpole et al., 2001; Ruiz Gonzalez et al., 2009; Viney and Catchpole, 1991). The rate at which fuels tends to this equilibrium is governed by the rate of diffusion of moisture through the fuel and is called the response time (Viney and Catchpole, 1991; Viney, 1991). This response time is defined as the time taken for the fuel to achieve about the $63 \%(1-1 / e)$ of the change from its initial moisture content to the EMC (Catchpole et al., 2001; Viney and Catchpole, 1991), and it primarily depends on fuel size (Catchpole et al., 2001; Viney, 1991).

Temperature $(T)$ and relative humidity $(\mathrm{RH})$ are the primary meteorological factors that affect EMC (Viney and Catchpole, 1991). Simard (1968) developed an empirical estimate of EMC based on a set of three equations that depend on the relative humidity (Eq. (1)). This model was calibrated for desorbing wood material (Viney, 1991) but it has been applied to fine fuels as well, such as in the case of the U.S. National Fire Danger Rating System (Bradshaw and 
Deeming, 1983).

$\mathrm{RH}<10 ; \mathrm{EMC}=0.03+0.2626 \mathrm{RH}-0.00104 \mathrm{RHT}$

$10 \leq \mathrm{RH}<50 ; \mathrm{EMC}=1.76+0.1601 \mathrm{RH}-0.02660 \mathrm{~T}$

$\mathrm{RH} \geq 50 ; \mathrm{EMC}=21.06-0.4944 \mathrm{RH}+0.005565 \mathrm{RH}^{2}$

\section{$-0.00063 \mathrm{RHT}$}

Another empirical model was developed along with the Canadian Fire Weather Index (Van Wagner, 1987). It was originally proposed by Van Wagner (1972) and later modified by VanWagner and Pickett (1985) to force the EMC converge at zero when RH tends to zero (Viney, 1991). This model take into account the hysteresis phenomenon. The equations for desorption $\left(\mathrm{EMC}_{d}\right)$ and adsorption $\left(\mathrm{EMC}_{w}\right)$ processes are:

$$
\begin{aligned}
\mathrm{EMC}_{d}= & 0.942 \mathrm{RH}^{0.679}+0.000499 e^{0.1 \mathrm{RH}} \\
& +0.18(21.1-T)\left(1-e^{-0.115 \mathrm{RH}}\right)
\end{aligned}
$$

$$
\begin{aligned}
\mathrm{EMC}_{w}= & 0.618 \mathrm{RH}^{0.753}+0.000454 e^{0.1 \mathrm{RH}} \\
& +0.18(21.1-T)\left(1-e^{-0.115 \mathrm{RH}}\right)
\end{aligned}
$$

On the other hand, a semi-empirical model to estimate EMC was proposed by Nelson (1984), who found a relationship between the EMC and the logarithmic change of the Gibbs free energy (Eq. (3)):

$\mathrm{EMC}=\frac{100}{B} \ln \left(\frac{-R T}{M \exp A} \ln \frac{\mathrm{RH}}{100}\right)$

where $R$ is the universal gas constant, $M$ is the molecular weight of water, and $A$ and $B$ are two parameters that must be evaluated for each fuel type and whether the involved process is desorption or adsorption. In addition, these coefficients may also vary with temperature.

Traditionally, these models have been applied with observed data from meteorological ground stations or with forecast data from numerical weather prediction (NWP) models. Ground stations provide accurate and updated observations of meteorological variables. However, weather networks are sparse and many times the stations are primarily located in agricultural or urban areas. For these reasons, several authors have recommended using forecast data based on NWP to replace weather observations, since NWP provide spatially distributed data at a reasonable resolution by downscaling and interpolating the surface meteorological variables (Aguado et al., 2007). Apart from the uncertainty caused by the downscaling and interpolation, it is worth noting that dealing with forecast data may deviate from observations due to the stochastic nature of the atmosphere. Finally, these EMC models serve as inputs, together with precipitation data, for drying algorithms in order to estimate the moisture of dead fuels (Bradshaw and Deeming, 1983; Van Wagner, 1987). A method proposed by Bradshaw and Deeming (1983) allows the estimation of fine dead fuels, with time lags of 1 and $10 \mathrm{~h}$, by simply using the EMC computed at the mid afternoon observation time. In Spain, Aguado et al. (2007) showed the relationship between moisture field samples of cured grass and litter with the $10-\mathrm{H}$ timelag fuel moisture model computed with Bradshaw's equations in a six-year period.

Remote sensing can provide spatially distributed information about the moisture content of fuels at an adequate spatial and temporal resolution. Most studies to estimate fuel moisture content with remote sensing data have dealt with live fuels, since certain wavelengths in the optical domain are related to vegetation greenness and leaf water content (Ceccato et al., 2002; Dennison et al., 2005; Fensholt and Sandholt, 2003; Garcia et al., 2008; Hao and Qu, 2007; Yebra et al., 2008).

\subsection{Air temperature estimation}

Empirical approaches to estimate air temperature with thermal infrared data can be found in Cresswell et al. (1999), Cristobal et al. (2008), Chokmani and Viau (2006), Jang et al. (2004), or Vogt et al. (1997). An interesting approach was proposed by Nemani and Running (1989) and Goward et al. (1994). This algorithm (hereafter called TVX) is based on the observed inverse linear relationship between the land surface temperature (LST) and a vegetation index (NDVI), as a measure of fractional vegetation cover. The Normalized Difference Vegetation Index (NDVI, Rouse et al. (1974)) is computed from Eq. (4):

$\mathrm{NDVI}=\frac{\rho_{\mathrm{NIR}}-\rho_{\mathrm{red}}}{\rho_{\mathrm{NIR}}+\rho_{\mathrm{red}}}$

where $\rho_{\text {NIR }}$ and $\rho_{\text {red }}$ are the near-infrared and red reflectances, respectively.

The TVX algorithm assumes that as the vegetation cover increases, the LST approaches the air temperature, since surface temperature of canopies tends to be similar to the temperature of air. Therefore, using a linear regression between LST and NDVI in a spatial window small enough to assume a constant atmospheric forcing, the air temperature can be retrieved by extrapolating this line to an NDVI that represents a full fractional vegetation cover (hereafter called $\mathrm{NDVI}_{\max }$ ). For more details about this algorithm the reader is addressed to Goward et al. (1994), Prihodko and Goward (1997), or Stisen et al. (2007).

\subsection{Vapour pressure estimation}

Most of the water vapour is concentrated in the lowest layers of the atmosphere. This decrease of water vapour through the atmosphere has been described by a power law (Smith, 1996). Smith (1996) proposed a logarithmic relationship between the total precipitable water in the atmosphere and the dew-point temperature in surface. This relationship is dependent on the atmospheric estate, expressed by the parameter $\lambda$, which is precisely the exponent of the power law and describes the atmospheric moisture profile. The author tabulated different values for $\lambda$ according to the season of the year and the latitude considered. However, he pointed out that better agreements could be obtained by adjusting this parameter to individual stations. Several authors emphasised the importance of the length of the observation period, with higher accuracies for longer periods such as monthly averages (Bolsenga, 1965; Schwarz, 1968; Smith, 1996). Despite of this, several authors have related surface humidity to atmospheric precipitable water in a daily basis with remote sensing data (Prince et al., 1998; Goward et al., 1994; Czajkowski et al., 2000). A good distribution of water through the atmospheric profile is required to get a reliable relation between the total atmospheric water content and the surface layer (Goward et al., 1994). Low pressure systems enhance the distribution of moisture, as well as incoming solar radiation during daytime, since surface heating favours vertical mixing (Schwarz, 1968).

\subsection{Precipitable water column estimation}

Precipitable water in the atmosphere $(W)$ is the main absorber of radiation in the thermal infrared region (Kleespies and McMillin, 1990), and therefore thermal remote sensing is very useful to estimate $W$. The effect of the attenuation of water vapour is different in adjacent wavebands. This differential absorption in the thermal infrared is the basis for split-window algorithms that estimate $W$ (Choudhury et al., 1995). These split-window algorithms are based on the decrease that water vapour causes on the atmospheric transmittance in wavelengths around $12 \mu \mathrm{m}$ compared to wavelengths around $11 \mu \mathrm{m}$ (Jedlovec, 1990; Kleespies and McMillin, 
1990). For instance, Choudhury et al. (1995) found a linear relationship, dependent upon the emissivities, between the brightness temperature difference in the split-window and $W$. However, the split window channels are also affected by both surface and air temperatures. Suggs et al. (1998) developed a physical based splitwindow algorithm, but their model required a priori initial guess values for temperature and moisture profiles, as well as for $W$ and LST. To avoid the use of a priori guess values, Kleespies and McMillin (1990) proposed the use of multiple observations under changing surface temperature conditions. With this approach, the dependence of both land surface and air temperature is eliminated. Assuming that $W$ keeps invariable between these two observations, the ratio of transmittance can be derived from Eq. (5).

$\frac{\tau_{11}}{\tau_{12}}=\frac{T_{11}^{A}-T_{11}^{B}}{T_{12}^{A}-T_{12}^{B}}$

where $\tau$ is the atmospheric transmittance, $T$ is the brightness temperature, the subscripts 11 and 12 refer to the split-window wavelengths (in $\mu \mathrm{m}$ ), and the superscripts $A$ and $B$ represent two different observation situations.

Jedlovec (1990) applied this methodology in a contextual algorithm for AVHRR images, under the assumption that $W$ is invariant within the scene. He found that $W$ is related to the variations of the split-window brightness temperatures through a logarithmic function. However, the assumption of invariant atmospheric conditions in the scene may limit the applicability of this approach in mountainous regions, where $W$ can change due to changes in topography (Li et al., 2003). To overcome with this limitation, both Schroedter-Homscheidt et al. (2008) and Sobrino and Romaguera (2008) proposed to exploit the daily cycle of temperature with MSG-SEVIRI in order to retrieve the transmittance ratio. Assuming equal emissivities, a polynomial function relates $W$ to the brightness temperature at two times. Compared to the thirdorder polynomial function proposed by Schroedter-Homscheidt et al. (2008), Sobrino and Romaguera (2008) showed that a second order polynomial function is enough accurate. Moreover, the coefficients of the polynomial function are view zenith angle dependent, and thus the final expression for retrieving the precipitable water vapour is shown in Eq. (6) (Sobrino and Romaguera, 2008).

$$
\begin{aligned}
& W=\text { a arg }^{2}+b \arg +c \\
& a=-15.1 \sec \theta+5.1 \\
& b=16.4 \sec \theta-2.8 \\
& c=0.336 \sec \theta-0.117 \\
& \arg =\frac{1}{\sec \theta} \ln \left(\frac{T_{11}^{A}-T_{11}^{B}}{T_{12}^{A}-T_{12}^{B}}\right)
\end{aligned}
$$

where $\theta$ is the view zenith angle. In order to avoid noisy effects, a minimum difference in brightness temperature in $T_{12}$ between both situations $A$ and $B$ is required (Schroedter-Homscheidt et al., 2008; Sobrino and Romaguera, 2008). This constraint may limit the applicability of the algorithm in snow-covered regions and in wetlands (Schroedter-Homscheidt et al., 2008).

This study is based on the hypothesis that it is feasible to retrieve dead fuel moisture content from remote sensing data through the application of the equilibrium moisture content approach, since thermal remote sensing has been proven to be useful to estimate both surface air temperature and water vapour pressure. The objective of this study is therefore to estimate the equilibrium moisture content through the retrieval or air temperature and relative humidity with remote sensing data. Air temperature will be estimated through the TVX algorithm whereas a model for estimating the vapour pressure from precipitable water retrieved with thermal infrared data will be developed. Images from Meteosat Second Generation-Spinning Enhanced Visible and Infrared Imager (MSG-SEVIRI) were selected due to its excellent temporal reso- lution (15 minutes) allowing a near-real time assessment of the moisture of dead fuels.

\section{Data}

\subsection{MSG-SEVIRI images}

The MSG-SEVIRI sensor provides images every $15 \mathrm{~min}$ at a spatial sampling of $3 \mathrm{~km}$ at sub-pixel nadir in 12 spectral channels, covering both the optical and thermal spectrum (Schmetz et al., 2002). The satellite is located at $0^{\circ}$ latitude and $0^{\circ}$ longitude, and covers Europe, Africa, the Middle East, and partly South America.

Visible and near infrared bands, centered at $0.6 \mu \mathrm{m}$ and $0.8 \mu \mathrm{m}$ wavelengths, as well as thermal images (centered at $10.8 \mu \mathrm{m}$ and $12.0 \mu \mathrm{m}$ wavelengths) from the Iberian Peninsula (Upper left corner: $44.393968^{\circ} \mathrm{N}, 10.894700^{\circ} \mathrm{W}$; Lower right corner: $35.184872^{\circ}$ $\mathrm{N}, 1.616629^{\circ} \mathrm{E}$ ) were extracted and resampled at a spatial resolution of $4 \mathrm{~km}$ for the year 2005. Images were acquired and preprocessed by the Department of Geography and Geology at the University of Copenhagen, Denmark. In addition, the EUMETSAT cloud mask product was also acquired for the same study period through the EUMETCAST service. This product is a simplification of the Cloud Analysis Image product, which is based on a series of threshold tests to detect and characterise clouds (EUMETSAT, 2007).

\subsection{Meteorological data}

Daily meteorological data have been obtained from two different sources. The Agro-climatic Information System for Irrigation (SIAR; Sistema de Información Agroclimática para el Regadío, http://www.mapa.es/siar/), which comprises 361 automatic agrometeorological weather stations; and the meteorological system of Galicia (MeteoGalicia, http://www.meteogalicia.es/), with 75 meteorological stations. Both sources have developed web applications to easily query and download their data at no cost.

Data from 284 stations were used for this study, located in the regions of Andalucía, Aragón, Castilla-La Mancha, Extremadura, Galicia, Murcia, Navarra, and La Rioja (Fig. 1). Most of the climatic variability in Spain has thus been covered by this set of stations as it is shown in Fig. 1. They were selected on the basis of being further than $8 \mathrm{~km}$ (2 MSG-SEVIRI pixels) from neighbour stations or the coast. Daily records of maximum and minimum relative humidity and temperature were extracted for the year 2005. 267 of these ground stations belong to the SIAR, and the remaining 17 belong to MeteoGalicia. In addition to these daily data, La Rioja SIAR service allows the download of hourly temperature and relative humidity. This hourly data has been used as well for validation purposes.

\section{Methods}

\subsection{Satellite processing}

Bands centered in $10.8 \mu \mathrm{m}$ and $12.0 \mu \mathrm{m}$ wavelengths for the Iberian Peninsula were used together with the EUMETSAT cloud mask to produce daily estimates of $W$. We exploited the air temperature daily cycle of MSG-SEVIRI applying the algorithm proposed by Sobrino and Romaguera (2008). They proposed to apply the algorithm in two instants, at 5:00 $\mathrm{h}$ and 11:00 h, and imposing the condition of a difference in the $12.0 \mu \mathrm{m}$ brightness temperature between these two situations higher than $10 \mathrm{~K}$. In order to ensure more valid observations, we have used a different scheme in the present study: (1) The early morning brightness temperature is searched in a temporal window between $5: 00 \mathrm{~h}$ and $8: 45 \mathrm{~h}$. The first cloud-free pixel within this temporal window is registered as $T_{11}^{A}$ and $T_{12}^{A}$. (2) Next, the near-noon brightness temperature is searched in a window between 9:00 $\mathrm{h}$ and 12:45 h. These tempera- 


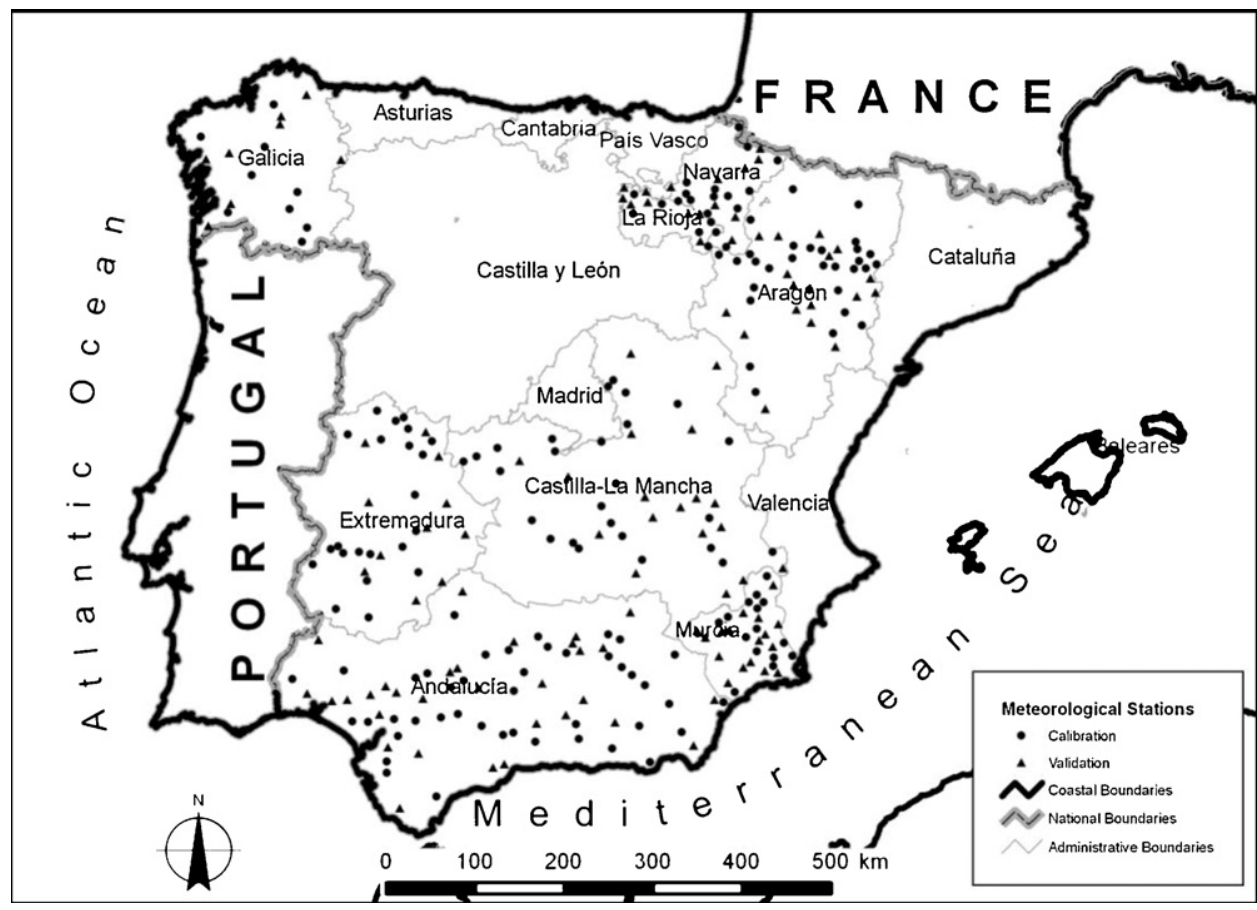

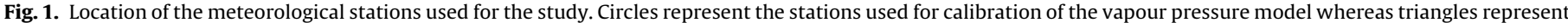
the stations used for validation of the model.

tures $\left(T_{11}^{B}\right.$ and $\left.T_{12}^{B}\right)$ were recorded as the first cloud-free observation in this window with $T_{12}^{B}-T_{12}^{A} \geq 10 \mathrm{~K}$, in order to avoid noisy effects (Sobrino and Romaguera, 2008). Another imposed constraint is that the difference between observations must be higher than $4 \mathrm{~h}$ to avoid a possible noisy temperature increase (SchroedterHomscheidt et al., 2008). Therefore, the time difference between observations has always been higher than $4 \mathrm{~h}$, which assured the minimum increase of $10 \mathrm{~K}$ in most of the surfaces, but lower than $8 \mathrm{~h}$, minimising thus the possibility of atmospheric changes (Kleespies and McMillin, 1990). However, the presence of clouds may drive the movement of humid air masses, and so the increase of the precipitable water content (Schroedter-Homscheidt et al., 2008; Viswanadham, 1981). A cloud quality check was therefore performed by counting the total number of cloud free observations during the temporal window.

Air temperature was retrieved by means of the TVX algorithm, which requires as inputs the NDVI and the LST as it was shown in Section 1.1. The NDVI was calculated from atmospherically corrected bands centered in $0.6 \mu \mathrm{m}$ and $0.8 \mu \mathrm{m}$ wavelengths in a scheme described by Stisen et al. (2007) and based on the SMAC model (Rahman and Dedieu, 1994). On the other hand, the LST was retrieved with a split-window algorithm (Sobrino and Romaguera, 2004). More details about the MSG-SEVIRI processing can be found in Stisen et al. (2007) and Nieto et al. (submitted for publication). The algorithm was applied in a moving window of $7 \times 7$ pixels. The value for the full fractional cover NDVI (NDVI $I_{\max }$ ) varied with the land cover type (Table 1 ) following the results of Nieto et al. (submitted for publication). The source for land cover classification was the MODIS Land Cover product, MCD12Q1 (Friedl et al., 2002), resampled at the MSG-SEVIRI pixel resolution ( $4 \mathrm{~km})$.

\subsection{Vapour pressure estimation}

Water vapour pressure $\left(e_{a}\right)$ can be linearly related to precipitable water $(W)$ through Eq. (7) (Smith, 1996)

$e_{a}=g \frac{W(\lambda+1)}{\delta}$ where $\delta=0.622$ is the ratio of specific gas constants of water vapour to dry air, $g$ is the acceleration of gravity, and $\lambda$ is the exponent of the power law that describes the atmospheric profile.

Multiple linear regression models (Eq. (8)) were fitted between the measured vapour pressure and the estimated precipitable water with MSG-SEVIRI data. In order to account for geographical variations, these models included the latitude of the weather station $(\varphi)$ as ancillary variable (Bolsenga, 1965; Reitan, 1963; Smith, 1996). One model for each season was calibrated (Smith, 1996; Viswanadham, 1981). A $60 \%$ of the available meteorological stations were used for calibration, leaving the remaining $40 \%$ for validation purposes as shown in Fig. 1.

$e_{a}=\beta_{0}+\beta_{1} W+\beta_{2} \varphi$

The daily vapour pressure at the ground stations was computed from the daily records of minimum and maximum relative humidity and temperature, following Eq. (9). This scheme is more appropriate than simply using mean values of temperature and relative humidity (Allen et al., 1998).

$e_{a}=\frac{1}{2}\left[e_{0}\left(T_{\max }\right) \frac{\mathrm{RH}_{\min }}{100}+e_{0}\left(T_{\min }\right) \frac{\mathrm{RH}_{\max }}{100}\right]$

where $e_{0}(T)$ is the saturation vapour pressure at temperature $T$, computed following Eq. (10) [from Murray (1967)]Tetens (1930).

$e_{0}(T)=0.6108 \exp \left(\frac{17.27 T}{T+237.3}\right)$

\subsection{Calculation of equilibrium moisture content}

The three models of equilibrium moisture content described in Section 1 were tested with this methodology. The model of Simard (1968), hereafter called S68, was chosen due to its simplicity and the wide spectrum in which it has been applied (Aguado et al., 2007). However this model has the disadvantage that it is neither continuous at the limits of the different intervals in its formulation (Eq. (1)) nor it takes into account hysteresis effects (Viney, 1991). The model of VanWagner and Pickett (1985), hereafter called 
Table 1

Calibrated TVX-NDVI $\max$ values corresponding to each of the IGBP biomes in the Iberian Peninsula.

\begin{tabular}{cll}
\hline Code & IGBP class & NDVI $_{\max }$ \\
\hline 1 & Evergreen needleleaved forest & 0.849 \\
2 & Evergreen broadleaved forest & 0.934 \\
4 & Deciduous broadleaved forest & 1.162 \\
5 & Mixed forests & 0.995 \\
6 & Closed shrublands & 0.915 \\
7 & Open shrublands & 0.803 \\
8 & Woody savannas & 0.835 \\
9 & Savannas & 0.777 \\
10 & Grasslands & 0.985 \\
12 & Croplands & 0.800 \\
13 & Urban and built-up & 0.780 \\
14 & Cropland/Natural vegetation mosaic & 0.937 \\
\hline
\end{tabular}

Source: Nieto et al. (submitted for publication).

vW85, was chosen because it has also been widely applied and it is continuous in the whole range of data. Uniquely the formulation corresponding to the desorption process (Eq. (2a)) was taken into account to be comparable with the $\mathrm{S} 68$ model. Finally, the semiempirical approach of Nelson (1984), hereafter called N84, was also compared. The values for coefficients $A$ and $B$ in Eq. (3) were those proposed by Nelson (1984) for Pinus ponderosa in a desorption process at a temperature of $25^{\circ} \mathrm{C}$.

To adjust the atmospheric relative humidity and temperature at the fuel-atmosphere interface, the factors shown in Table 2 were used as they were proposed by Bradshaw and Deeming (1983). This table requires as ancillary variable the sky condition. Therefore, a daily sky condition was computed, in a pixel basis, as the proportion cloud MSG-SEVIRI observations to the total of observations between $8: 00 \mathrm{~h}$ and 16:00 $\mathrm{h}$. For this purpose the standard SEVIRI cloud mask product was used (EUMETSAT, 2007).

15 min relative humidity $(\mathrm{RH})$ was computed with observations between $8: 00 \mathrm{~h}$ and $16: 00 \mathrm{~h}$, since it is the time window with available air temperature estimations (Eq. (11)).

$\mathrm{RH}(\%)=100 \frac{e_{a}}{e_{0}}$

The saturation vapour pressure has been computed with Eq. (10) by substituting the retrieved $15 \mathrm{~min}$ TVX temperature into $T$.

\subsection{Validation}

Vapour pressure was assessed with daily data from the agrometeorological stations that have not been used for calibration (40\% of the dataset, Fig. 1). On the other hand, the hourly maximum temperature and the minimum relative humidity estimates were validated with the hourly data from the ground stations in La Rioja that were not used in the calibration process. Finally, the transfer of errors from these estimates to the EMC models were assessed as well with data from La Rioja ground stations.

The bias, the mean absolute error (MAE), and the root mean square error (RMSE) were computed as error measurements (Willmott, 1982; Willmott and Matsuura, 2005). The slope $b$ and the intercept $a$ of the regression between the observed versus the predicted (Pineiro et al., 2008) as well as the Pearson corre-
Table 3

Seasonal and annual descriptive statistics for $\lambda$ parameter. $\lambda$ values below 0 have been discarded for the analyses.

\begin{tabular}{lrrrrr}
\hline Season & $N$ & \multicolumn{1}{l}{ Min } & Mean & \multicolumn{1}{c}{ Max } & S.D. \\
\hline Winter & 9849 & 0.01 & 2.67 & 47.46 & 2.71 \\
Spring & 13373 & 0.02 & 2.64 & 46.26 & 2.95 \\
Summer & 17112 & 0.12 & 2.77 & 102.82 & 2.21 \\
Autumn & 8731 & 0.07 & 3.43 & 90.99 & 3.51 \\
Year & 49065 & 0.01 & 2.83 & 102.82 & 2.57 \\
\hline
\end{tabular}

lation coefficient $r$ were computed as agreement measures. Finally, in order to allow an accuracy comparison between the different estimates (meteorological variables and modelled EMCs), Theil's decomposition of errors was performed (Smith and Rose, 1995). Theil's coefficients (Eq. (12)) partition the sum of the squared errors between the observed and the predicted in a proportion associated with (1) mean differences between the observed and predicted values, $U_{\text {bias }}$; (2) deviations from the $1: 1$ line, $U_{\text {slope }}$; and (3) the unexplained variance, $U_{\text {error }}$.

$$
\begin{aligned}
U_{\text {bias }} & =\frac{N(\bar{O}-\bar{P})^{2}}{\sum(O-P)^{2}} \\
U_{\text {slope }} & =\frac{(b-1)^{2} \sum(P-\bar{P})^{2}}{\sum(O-P)^{2}} \\
U_{\text {error }} & =\frac{\sum(\hat{O}-O)^{2}}{\sum(O-P)^{2}}
\end{aligned}
$$

where $N$ is the number of elements, $O$ and $P$ are the observed and predicted values, respectively; $\bar{O}$ and $\bar{P}$ are the observed and predicted mean, respectively; and $\hat{O}=a+b P$. Since the coefficients represent a proportion of the total error, the sum of the three coefficients is 1 . A good model should neither deviate from the 1:1 line nor have a bias. Therefore $U_{\text {bias }}$ and $U_{\text {slope }}$ should be close to zero whereas $U_{\text {error }}$ should be close to unity.

\section{Results}

A total of 59,507 valid estimations of $W$ located over the ground stations were obtained during the year 2005. However, cases with a low precipitable water $(W<0.1 \mathrm{~cm})$ were suppressed in following analyses in order to avoid noisy effects caused by the sensor signal in very dry atmospheres (Kleespies and McMillin, 1990). This filter left 59,281 cases. When crossing the retrieved $W$ with the calculated vapour pressure at the ground stations, a total of 49,166 cases were obtained. The $\lambda$ parameter, which describes the atmosphere profile, was then computed by reordering Eq. (7). Assuming that moisture decreases through the atmosphere with the altitude, this parameter must be positive. Therefore, all cases with negative values of $\lambda$ were discarded for future analysis. Table 3 shows the descriptive statistics of this parameter. The annual mean is 2.83 , being the mean values higher in autumn and summer (3.43 and 2.77 , respectively) than during spring and winter (2.64 and 2.67, respectively).

Once these filters were applied, 29,651 cases were used to calibrate the daily vapour pressure estimation, leaving other 19,414 cases to validate the model. One model was calibrated per sea-

Table 2

\begin{tabular}{|c|c|c|c|c|}
\hline \multicolumn{5}{|c|}{ Sky condition } \\
\hline & Clear (0-0.1) & Scattered $(0.1-0.5)$ & Broken (0.5-0.9) & Overcast (0.9-1) \\
\hline$T$ add (celsius) & 13.9 & 10.6 & 6.7 & 2.8 \\
\hline RH multiply & 0.75 & 0.83 & 0.91 & 1 \\
\hline
\end{tabular}

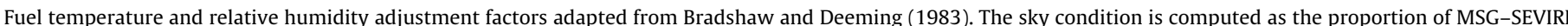
cloud detections between 8:00 h and 16:00 h. 
Table 4

Multiple linear regression between water vapour pressure and precipitable water $(W)$ and Latitude.

\begin{tabular}{llllll}
\hline Season & $N$ & $R^{2}$ & Intercept & $W(\mathrm{~cm})$ & Latitude $\left(^{\circ}\right)$ \\
\hline Winter & 5935 & $0.29^{*}$ & $1.00^{*}$ & $0.20^{*}$ & $-0.017^{*}$ \\
Spring & 8081 & $0.30^{*}$ & $0.58^{*}$ & $0.22^{*}$ & -0.001 \\
Summer & 10363 & $0.32^{*}$ & $1.28^{*}$ & $0.26^{*}$ & $-0.017^{*}$ \\
Autumn & 5272 & $0.30^{*}$ & $1.21^{*}$ & $0.22^{*}$ & $-0.019^{*}$ \\
Year & 29651 & $0.47^{*}$ & $0.83^{*}$ & $0.32^{*}$ & $-0.012^{*}$ \\
\hline
\end{tabular}

* Significant coefficients $(p<0.01)$ were flagged with an asterisk.

son during the year 2005. The results are shown in Table 4. The validation of the vapour pressure (Table 5) showed no significant bias $\left(0.002 \mathrm{kPa}, U_{\text {bias }}=0.00\right)$ and an accuracy of $0.182 \mathrm{kPa}$ in terms of MAE. In addition, the slope was very close to $1(b=1.030$, $U_{\text {slope }}=0.00$, see Fig. $2 \mathrm{a}$ ). Therefore, the error contribution in the model may be assigned completely to the unexplained variance $\left(U_{\text {error }}=1\right)$, with a Pearson correlation coefficient of 0.77 .

Fig. 3 shows the spatial accuracy of this model. The mean absolute error was computed for each ground station used for validation. In most of the ground stations the estimates showed a
MAE between $0.13 \mathrm{kPa}$ and $0.18 \mathrm{kPa}$. The highest errors are found in Galicia and in Murcia, showing therefore no pattern related with latitude or longitude. In the case of Galicia this issue can be caused because we are dealing with two a different meteorological networks, and sensors used for measuring air temperature and humidity are different both networks (tipically Geonica STH-5031 sensors used in Meteogalicia vs. Vaisala HMP45 sensors used in the SIAR network).

Air temperature, relative humidity, vapour pressure deficit and equilibrium moisture content were thus estimated in the corresponding MSG-SEVIRI pixels over the ground stations of La Rioja. Hourly maximum and minimum air temperature were obtained from the retrieved maximum $15 \mathrm{~min}$ air temperature estimated from MSG-SEVIRI. Hourly saturation vapour pressure was then computed averaging the saturation vapour pressures at the minimum and maximum temperatures using Eq. (9). Hourly relative humidity as well as vapour pressure deficit were then computed from the estimated hourly saturation vapour pressure and the MSG-SEVIRI daily vapour pressure. Finally, hourly relative humidity and air temperature, were combined to estimate the hourly equilibrium moisture content. The near surface meteorological
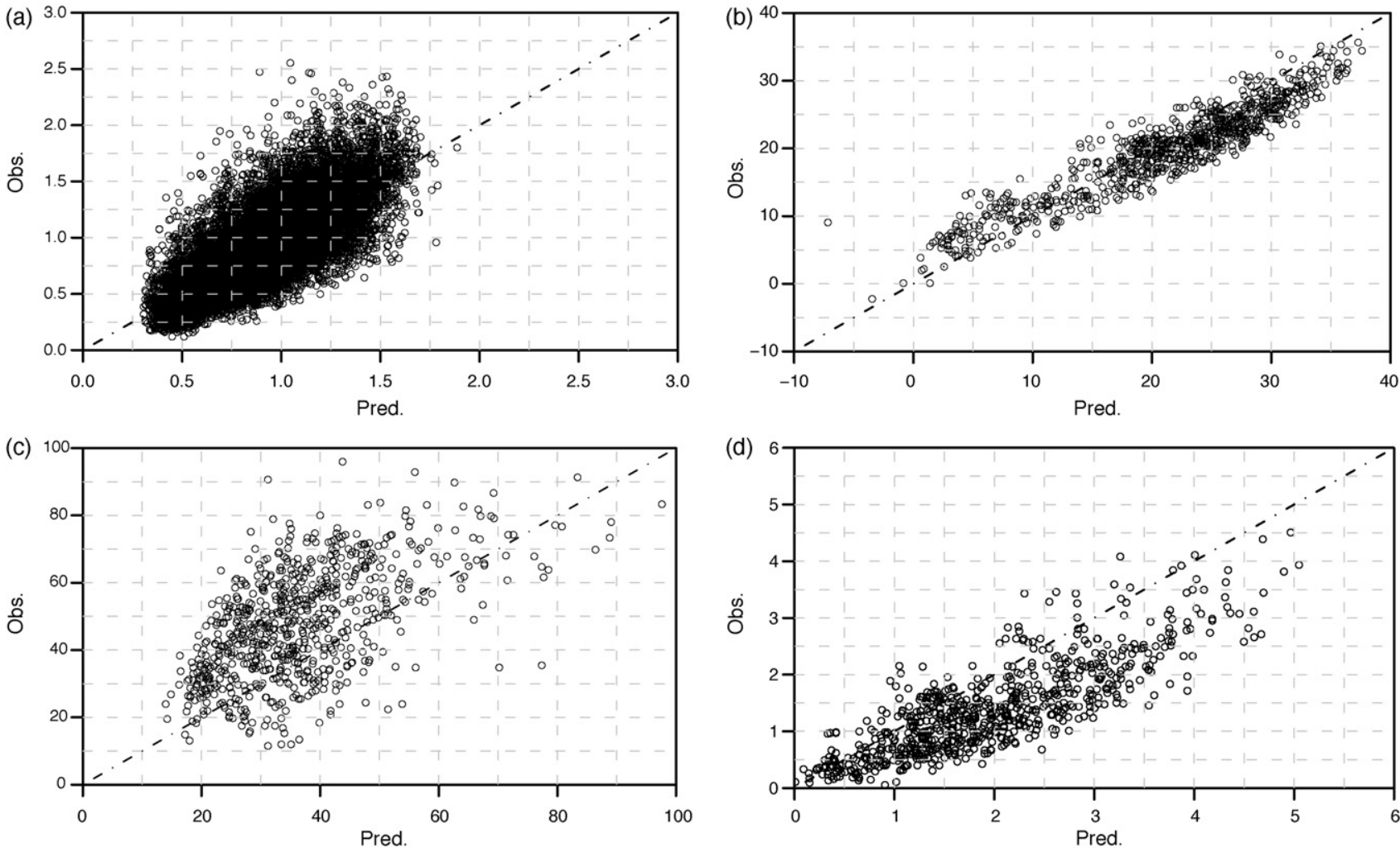

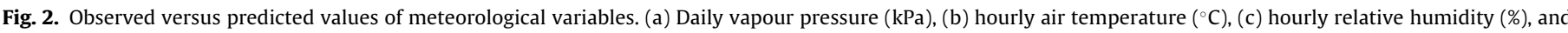
(d) hourly vapour pressure deficit $(\mathrm{kPa})$

\section{Table 5}

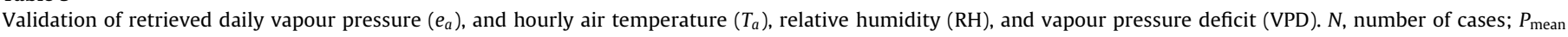

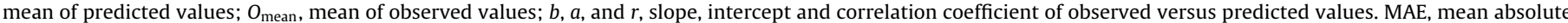

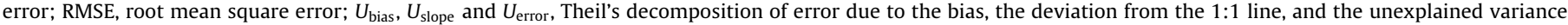
respectively.

\begin{tabular}{|c|c|c|c|c|c|c|c|c|c|c|c|}
\hline & \multirow[t]{2}{*}{$N$} & \multirow[t]{2}{*}{$P_{\text {mean }}$} & \multirow[t]{2}{*}{$O_{\text {mean }}$} & \multicolumn{3}{|c|}{$(O$ vs. $P$ ) } & \multirow[t]{2}{*}{ MAE } & \multirow[t]{2}{*}{ RMSE } & \multirow[t]{2}{*}{$U_{\text {bias }}$} & \multirow[t]{2}{*}{$U_{\text {slope }}$} & \multirow[t]{2}{*}{$U_{\text {error }}$} \\
\hline & & & & $b$ & $a$ & $r$ & & & & & \\
\hline$e_{a}(\mathrm{kPa})$ & 19414 & 0.91 & 0.91 & 1.03 & -0.03 & 0.77 & 0.18 & 0.24 & 0.00 & 0.00 & 1.00 \\
\hline$T_{a}\left({ }^{\circ} \mathrm{C}\right)$ & 853 & 21.3 & 19.8 & 0.75 & 3.76 & 0.94 & 2.9 & 3.5 & 0.18 & 0.36 & 0.46 \\
\hline $\mathrm{RH}(\%)$ & 738 & 36.5 & 47.7 & 0.72 & 21.56 & 0.57 & 14.8 & 17.8 & 0.40 & 0.04 & 0.56 \\
\hline VPD (kPa) & 738 & 1.97 & 1.4 & 0.67 & 0.08 & 0.82 & 0.66 & 0.81 & 0.51 & 0.17 & 0.32 \\
\hline
\end{tabular}




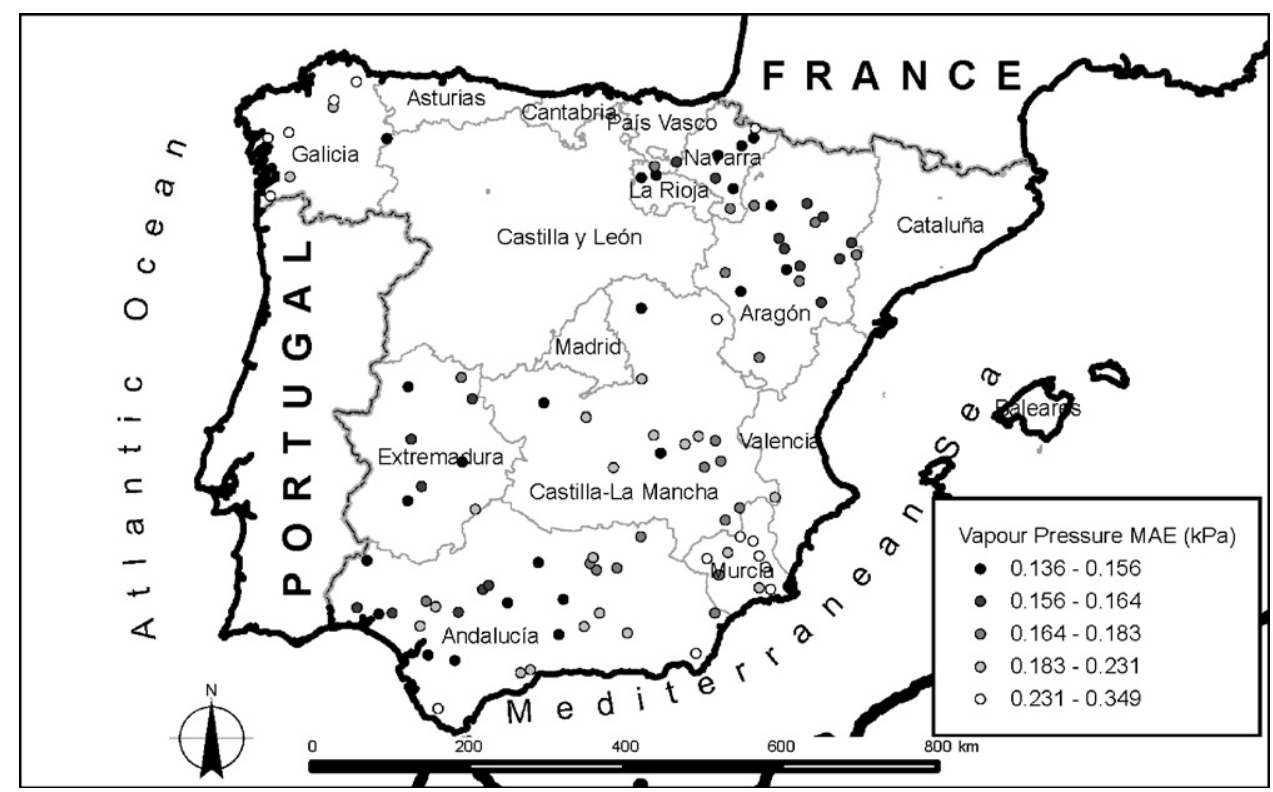

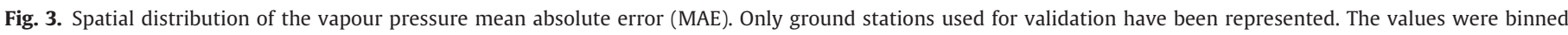
following a geometric series

estimates were scaled to the temperature and relative humidity at the fuel-atmosphere interface, according to Table 2, using the sky condition variable computed through the MSG-SEVIRI cloud mask data (EUMETSAT, 2007).

Table 5 shows the validation assessment of the meteorological MSG-SEVIRI estimates with the hourly ground measurements in La Rioja stations. Air temperature shows a MAE of $2.9^{\circ} \mathrm{C}$ and a RMSE of $3.5^{\circ} \mathrm{C}$, with a mean bias of $1.5^{\circ} \mathrm{C}$. The bias is responsible of $18 \%$ of the total error, whereas the lack of unity slope $(b=0.75)$ and the unexplained variance represents the $36 \%$ and $46 \%$ of the error, respectively. Fig. 2(b) shows the scatterplot of observed versus predicted. This figure shows that the model tends to underprediction at low temperatures and to overprediction at high temperatures.

Both relative humidity (RH) and vapour pressure deficit (VPD) show similar patterns, with an underestimation of humidity (mean bias of $-12.2 \%$ and $0.564 \mathrm{kPa}$ respectively for $\mathrm{RH}$ and VPD). $\mathrm{RH}$ showed a MAE $=14.7 \%$ and $\mathrm{RMSE}=17.8 \%$, whereas VPD had an $\mathrm{MAE}=0.663 \mathrm{kPa}$ and an RMSE $=0.806 \mathrm{kPa}$. Most of the error in estimating $\mathrm{RH}$ comes from the unexplained variance by the model $\left(U_{\text {error }}=56 \%\right)$, followed by the bias $\left(U_{\text {bias }}=40 \%\right)$. As it can be seen in Fig. 2(c) and (d), the estimated RH shows a poorer performance in explaining the observed variance compared to the VPD (Pearson correlation coefficient of 0.57 versus 0.82 ).

Three models of EMC were computed from the retrieved hourly data after applying the correction factors to temperature and relative humidity of Table 2 . The three models tend to underestimate, with mean bias of $-1.48 \%,-2.09 \%$ and $-1.41 \%$, respectively for the S68, vW85 and N84 models (Table 6 and Fig. 4). N84 showed the lowest MAE, with a value of $1.86 \%$, which represents $19.5 \%$ of to the observed mean $\left(O_{\text {mean }}=9.52 \%\right)$. On the other hand, S68 and vW85 showed MAEs of $1.93 \%$ and $2.73 \%$ respectively, representing the $28.2 \%$ and $31.3 \%$ of the observed means ( $6.85 \%$ and $8.73 \%$, respectively). The three models have a similar slope of the regression of the observed versus predicted values ( $b$ values ranging between 0.78 and 0.79 ), but the vW85 model explained the highest variance of the three models (Pearson correlation coefficient of 0.71 compared to 0.62 and 0.61 for S68 and N84, respectively). In the three models, near a $60 \%$ of the error is due to the unexplained variance, whereas the proportion of the error associated to the bias is close to the $40 \%$. The contribution to the errors by the lack of slope unity is almost insignificant for all three models ( $4 \%$ in the worst case).

\section{Discussion}

The proposed methodology aimed to estimate the equilibrium moisture content of dead fuels in a sequential manner. First relating the remotely sensed atmospheric precipitable water to the vapour pressure in surface; secondly, with the estimation of the air temperature by means of the TVX algorithm; thirdly, the 15 minute air temperature and the daily vapour pressure were combined to obtain the relative humidity every $15 \mathrm{~min}$; and finally, by calculating the EMC with the estimated air temperature and relative humidity. Each one of these tasks is subject to error. The source of possible errors for each task as well as the transfer of errors in EMC models will be discussed in the following paragraphs.

\subsection{Vapour pressure}

The vapour pressure is related to the atmospheric precipitable water through the $\lambda$ parameter. In this study, $\lambda$ values for each season ranged between 2.6 and 3.4 (Table 3), having the same order that the originally proposed values by Smith (1996). Indeed, those tabulated values ranged from 2.7 to 3.1 in latitudes between $30^{\circ}$ and $50^{\circ}$. The values obtained in our study are however based on only one year and in a specific location compared to the values from Smith (1996), who used a more global and a longer timeseries dataset to tabulate the values of $\lambda$. Descriptive statistics in Table 3 show as well that the highest variability in atmospheric conditions is shown in spring and in autumn, with the highest standard deviation in $\lambda$. The other extreme is summer, with a low standard deviation showing that the daily atmospheric profile becomes more stable amongst days.

The linear regressions between the vapour pressure and the precipitable water showed low coefficients of determination $R^{2}$ (Table 4). This was however expected since several authors already pointed out the highly variability of the atmospheric profile in a hourly to daily basis (Bolsenga, 1965; Reitan, 1963; Schwarz, 1968; Smith, 1996). An estimation of decadal or monthly averages of vapour pressure would lead to an increase of the explained variance by the proposed model, and therefore it should be expected 
Table 6

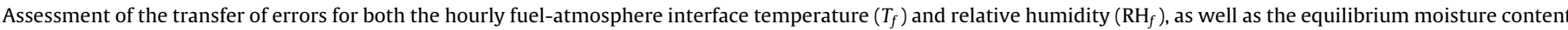

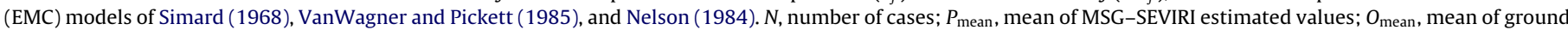

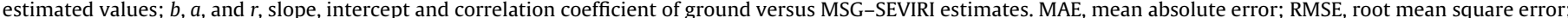
$U_{\text {bias }}, U_{\text {slope }}$ and $U_{\text {error }}$, Theil's decomposition of error due to the bias, the deviation from the 1:1 line, and the unexplained variance, respectively.

\begin{tabular}{|c|c|c|c|c|c|c|c|c|c|c|c|}
\hline & \multirow[t]{2}{*}{$N$} & \multirow[t]{2}{*}{$P_{\text {mean }}$} & \multirow[t]{2}{*}{$O_{\text {mean }}$} & \multicolumn{3}{|c|}{$(O$ vs. $P)$} & \multirow[t]{2}{*}{ MAE } & \multirow[t]{2}{*}{ RMSE } & \multirow[t]{2}{*}{$U_{\text {bias }}$} & \multirow[t]{2}{*}{$U_{\text {slope }}$} & \multirow[t]{2}{*}{$U_{\text {error }}$} \\
\hline & & & & $b$ & $a$ & $r$ & & & & & \\
\hline$T_{f}\left({ }^{\circ} \mathrm{C}\right)$ & 738 & 35.7 & 33.8 & 0.78 & 5.83 & 0.92 & 2.9 & 3.4 & 0.32 & 0.21 & 0.47 \\
\hline $\mathrm{RH}_{f}(\%)$ & 738 & 28.5 & 37.4 & 0.78 & 15.27 & 0.59 & 11.6 & 14.2 & 0.40 & 0.02 & 0.58 \\
\hline EMC S68 (\%) & 738 & 5.37 & 6.85 & 0.78 & 2.66 & 0.62 & 1.93 & 2.35 & 0.40 & 0.03 & 0.57 \\
\hline EMC vW85 (\%) & 738 & 6.63 & 8.73 & 0.79 & 3.49 & 0.71 & 2.73 & 3.29 & 0.41 & 0.04 & 0.55 \\
\hline EMC N84 (\%) & 738 & 8.11 & 9.52 & 0.78 & 3.20 & 0.61 & 1.86 & 2.26 & 0.39 & 0.03 & 0.58 \\
\hline
\end{tabular}
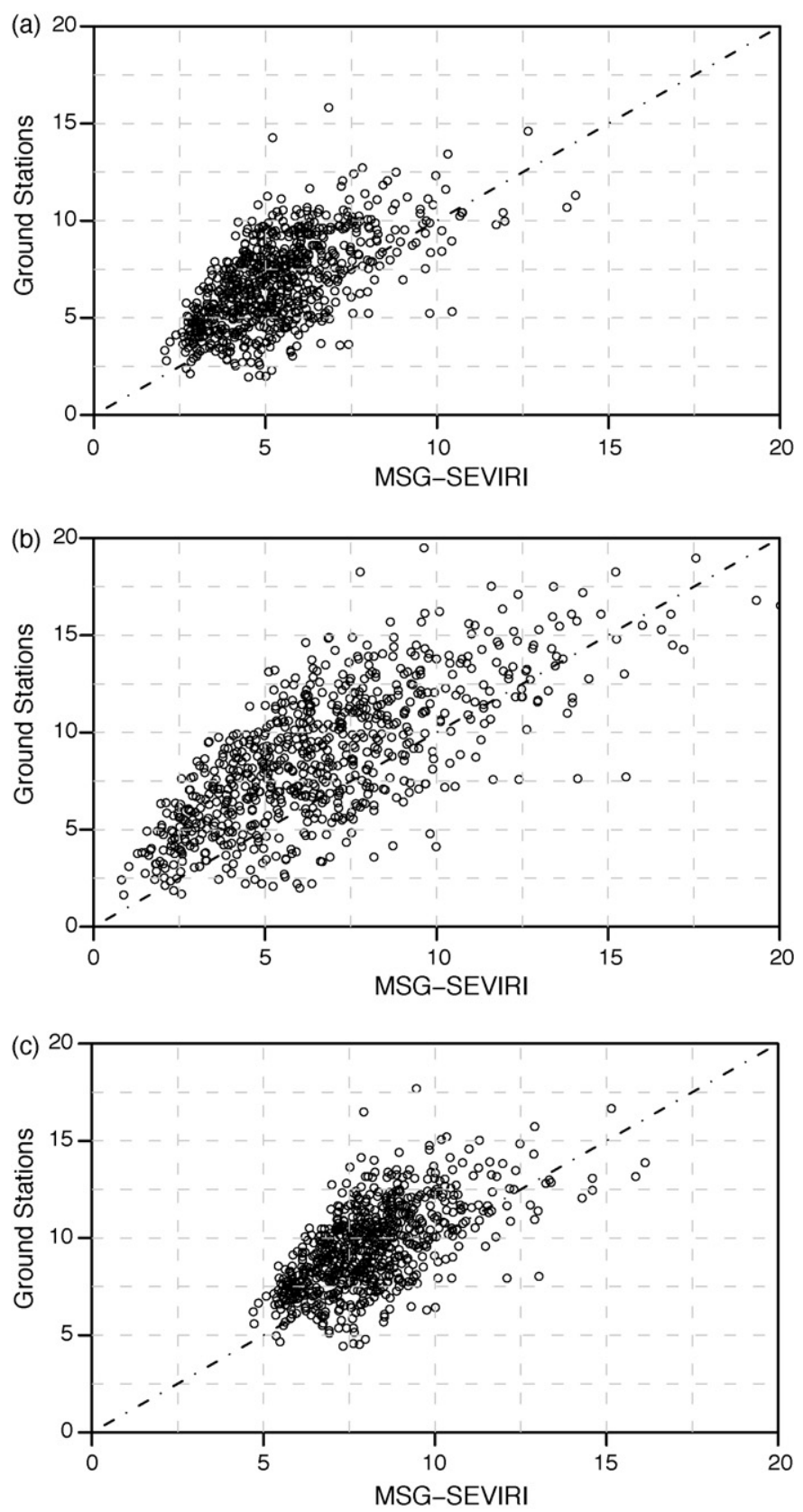

Fig. 4. Ground versus MSG-SEVIRI estimates of equilibrium moisture content (\%). (a) Simard (1968), (b) VanWagner and Pickett (1985), and (c) Nelson (1984) models higher $R^{2}$ values. However, the validation of this model showed its feasibility, showing no bias and a regression slope of observed versus predicted very close to $1(b=1.03)$. Therefore, all of the errors in vapour pressure estimation $(\mathrm{MAE}=0.182 \mathrm{kPa})$ were caused by the unexplained variance of the model $\left(U_{\text {error }}=1.00\right)$. The uncertainty in the retrieval of vapour pressure increased with errors of vapour pressure measurements, such as sensor noise or failure in the assumption of daily constant vapour pressure, as well as with errors in the MSG-SEVIRI precipitable water algorithm, which had an expected accuracy around $0.5 \mathrm{~cm}$ (Sobrino and Romaguera, 2008). A reduction of these errors should improve the vapour pressure estimates and thus an additional increase of the explained variance by the model.

From Table 4 and Eq. (8), it is evident that vapour pressure decreases with latitude, when precipitable water is constant. This trend can be observed as well with the tabulated values of Smith (1996), where $\lambda$ tends to decrease with higher latitudes. In addition, the effect of latitude seems to be constant through the year, with values of $\beta$ coefficient between -0.17 and -0.19 with the exception of spring, which had a very low and not significant coefficient $(p=0.39)$. The moisture atmospheric profile in the Iberian Peninsula during spring seems therefore invariant with latitude, at least during the year 2005. Further research should address this issue, trying to expand the dataset of observations with additional years.

\subsection{Air temperature}

Estimated air temperature showed good accuracy $\left(\mathrm{MAE}=2.9^{\circ} \mathrm{C}\right.$ and RMSE $=3.5^{\circ} \mathrm{C}$ ) with the observed hourly maximum temperature in the validation sites of La Rioja. This result improves the estimates from Nieto et al. (submitted for publication) of $5^{\circ} \mathrm{C}$ in RMSE in Spain. The improvement in the current study can be caused by the fact that the authors in the original study used to calibrate and validate interpolated daily maximum air temperature instead of measured air temperature in ground stations.

\subsection{Relative humidity}

Humidity has been computed in terms of vapour pressure deficit as well as relative humidity. Similar results in VPD accuracy, have been found in Goward et al. (1994), with an RMSE of $0.7 \mathrm{kPa}$ versus an RMSE $=0.8 \mathrm{kPa}$ obtained in our study, but both studies improves the results obtained by Prince et al. (1998), with an RMSE $=1.1 \mathrm{kPa}$. In our study and in Goward et al. (1994) the surface humidity was locally calibrated with ground data, whereas Prince et al. (1998) directly applied the tabulated values of $\lambda$ shown in Smith (1996). As Smith (1996) pointed out in his paper, better relationships between the precipitable water and surface humidity are expected to be obtained from fittings with individual stations. The modelled relative humidity explained less variance compared to VPD (Table 5). Besides, Fig. 2c shows that the disagreement between the observed and the predicted values of RH is higher with increasing RH. Indeed, 


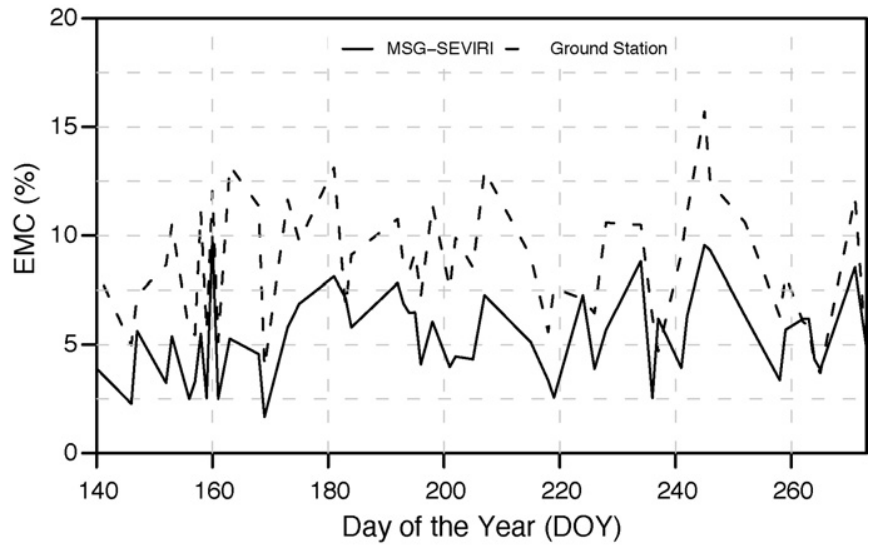

Fig. 5. Temporal evolution of VanWagner and Pickett (1985) equilibrium moisture content. Dashed timeseries represents the EMC calculated with data from the station in Santo Domingo de la Calzada (La Rioja, $42.1433^{\circ} \mathrm{N}, 2.9423^{\circ} \mathrm{W}$ ). Plain timeseries represent the EMC calculated with MSG-SEVIRI meteorological proxies for the same location.

by computing the derivatives of RH and VPD with air Temperature (Eqs. (13) and (14)), it can be seen that RH is more sensitive to $T$ variations (namely inaccuracies) than VPD. In addition VPD variations with temperature are insensitive to vapour pressure. It is thus expected that the accuracy in estimating RH will be lower with low temperatures. On the contrary, low temperatures will increase the accuracy of VPD estimations. However, these inaccuracies in RH are reduced at higher air temperatures, when the highest fire danger is expected to occur.

$$
\begin{gathered}
\frac{d \mathrm{RH}}{d T}=-4098 \frac{e_{a}}{e_{0}(T+237.3)^{2}} \quad \frac{d \mathrm{RH}}{d e_{a}}=\frac{1}{e_{0}} \\
\frac{d \mathrm{VPD}}{d T}=4098 \frac{e_{0}}{(T+237.3)^{2}} \quad \frac{d \mathrm{VPD}}{d e_{a}}=-1
\end{gathered}
$$

In our study, vapour pressure estimates showed neither bias nor deviations from the 1:1 line, and thus it can be inferred that most of the inaccuracies in bias and deviations from the 1:1 line in relative humidity are caused by the air temperature estimates. On the other hand, errors caused by the unexplained variance in humidity are mostly owing to the estimates of vapour pressure. It is clear that improvements in the retrieval of precipitable water, vapour pressure, and especially in air temperature, will improve the estimates of VPD and RH (Czajkowski et al., 2000; Prince et al., 1998). Finally, noise removal caused by cloud contaminated pixels becomes crucial in precipitable water (Jedlovec, 1990; SchroedterHomscheidt et al., 2008; Suggs et al., 1998) and in air temperature (Czajkowski et al., 2000; Prince et al., 1998) estimations.

\subsection{Equilibrium moisture content}

Temperature and relative humidity at the fuel-atmosphere interface showed the same pattern as the air measurements, with a trend to overestimate in temperature and to underestimate in relative humidity. This trend causes the systematic underestimation of the equilibrium moisture content. As an example of this underestimation in EMC, Fig. 5 shows the trend of EMC with MSG-SEVIRI data and with ground data for the station of Santo Domingo de la Calzada (La Rioja). Al thought the EMC from MSG-SEVIRI systematically underestimates the EMC computed with meteorological ground data, both timeseries show the same trend.

Although the slope of the EMC models between the values calculated with ground measurements and those estimated with MSG-SEVIRI is around 0.78 , the error contribution caused by the slope is almost negligible ( $U_{\text {slope }} \approx 4 \%$ in the three models). Nev-
Table 7

Pearson correlation coefficient between the absolute residuals of retrieved param-

\begin{tabular}{|c|c|c|c|c|c|}
\hline & & \multicolumn{2}{|c|}{ Observed values } & \multicolumn{2}{|c|}{ Absolute residua } \\
\hline & & $T_{f}$ & $\mathrm{RH}_{f}$ & $T_{f}$ & $\mathrm{RH}_{f}$ \\
\hline \multirow[t]{3}{*}{ Absolute Residual } & EMC S68 & -0.24 & 0.63 & 0.42 & 0.99 \\
\hline & EMC vW85 & -0.11 & 0.53 & 0.53 & 0.98 \\
\hline & EMC N84 & -0.23 & 0.63 & 0.42 & 1.00 \\
\hline
\end{tabular}
eters and the observed meteorological values.

ertheless, deviations from the 1:1 line are almost caused by a few cases with the highest EMC values. Indeed, below a certain MSG-SEVIRI EMC value, the slope between the observed and the predicted is not significantly $(p<0.01)$ different for 1 . This value is approximately $7.5 \%$ for $S 68$ (678 out of 738 cases are below that value), 10\% for vW85 (641 cases), and 115 for N84 (697 cases).

EMC models are more sensitive to changes in relative humidity than to changes in temperature (Ruiz Gonzalez et al., 2009), and therefore the accuracy of EMC is very dependent on the accuracy in the $\mathrm{RH}$ retrieval. This issue can be empirically observed in Table 7 , where the Pearson correlation coefficient is shown between the residuals of the retrieved EMC and the one calculated from ground meteorological values. The residuals of the EMC models increase with increasing relative humidity and decreasing temperature and this relationship is stronger with the humidity than with the temperature. Finally, the magnitude of the error in EMC is completely dependent on the errors in relative humidity $(r \approx 1)$ between the residuals of EMC and residuals of $\mathrm{RH}$. An appropriate estimate of relative humidity is therefore the critical factor in the retrieval of EMC with remote sensing data.

\section{Conclusion}

A methodology to estimate the equilibrium moisture content of dead fuel with MSG-SEVIRI images have been proposed in this study. Air temperature was estimated every $15 \mathrm{~min}$ by combining the NDVI and land surface temperature from SEVIRI using the TVX approach (Goward et al., 1994). On the other hand, daily vapour pressure was estimated by relating the daily precipitable water, retrieved with a split-window algorithm developed for MSG-SEVIRI (Sobrino and Romaguera, 2008), to the surface vapour pressure calculated with data from meteorological stations. The modelled vapour pressure showed good accuracy with no bias and no deviations from the slope unity between the observed and predicted. On the other hand, estimates of air temperature deviate from the 1:1 line and show a positive bias. Vapour pressure and air temperature were then combined to estimate the relative humidity. Since estimated air temperature tends to overpredict, the retrieved relative humidity tends to be underestimated. Finally, when these estimates of air temperature and relative humidity are combined to calculate the EMC, the results logically showed a negative bias compared to EMC calculated with surface meteorological data. It is crucial therefore to obtain unbiased estimates of air temperature to avoid this underprediction on EMC. Further research should address to get better estimates of air temperature. This task could be achieved by obtaining better radiometric corrections for the atmospheric and bidirectional effects in NDVI. In addition, the algorithm developed in Nieto et al. (submitted for publication) for estimating the $\mathrm{NDVI}_{\max }$ aimed the minimisation of residuals in the air temperature estimates, although these estimates may be biased from ground data. Therefore, an alternative method for the estimation of $\mathrm{NDVI}_{\max }$ that produces unbiased estimates of air temperature would be addressed in future research. Finally, an improvement in the estimation of precipitable water becomes as well important since it affects the retrieval of LST and the vapour pressure estimation. 


\section{Acknowledgements}

Part of this research has been done during a visiting stay at the Department of Geography and Geology at the University of Copenhagen (Denmark). The first author has been funded by the Spanish Ministry of Science through the FPI scholarship BES-2005-7801. Special thanks to Flemming Andersen and Simon Stisen from the University of Copenhagen for providing the MSG atmospherically corrected images. Also thanks to the Spanish Ministry of Agriculture, Food and Fisheries, the regional centres of the Agro-climatic Information System for Irrigation, and Meteogalicia for providing the meteorological database.

\section{References}

Aguado, I., Chuvieco, E., Boren, R., Nieto, H., 2007. Estimation of dead fuel moisture content from meteorological data in Mediter ranean areas, applications in fire danger assessment. International Journal of Wildland Fire 16, 390-397.

Allen, R., Pereira, L., Raes, D., Smith, M., 1998. Crop evapotranspiration: guidelines for computing crop water requirements. FAO Irrigation and Drainage Papers 56. Food and Agriculture Organization.

Bolsenga, S.J., 1965. The relationship between total atmospheric water vapor and surface dew point on a mean daily and hourly basis. Journal of Applied Meteorology 4, 430-432.

Bradshaw, B.S., Deeming, J.E., 1983. The 1978 National Fire Dan ger Rating System. Technical documentation. Technical Report. USDA, Forest Service. Ogden, Utah.

Catchpole, E.A., Catchpole, W.R., Viney, N.R., McCaw, W.L., Marsden-Smedley, J.B., 2001. Estimating fuel response time and predicting fuel moisture content from field data. International Journal of Wildland Fire 10, 215-222.

Ceccato, P., Gobron, N., Flasse, S., Pinty, B., Tarantola, S., 2002. Designing a spectral index to estimate vegetation water content from remote sensing data: Part 1 theoretical approach. Remote Sensing of Environment 82, 188-197.

Chokmani, K., Viau, A.A., 2006. Estimation of the air temperature and the vapour quantity in atmospheric water with the help of the AVHRR data of the NOAA. Canadian Journal of Remote Sensing 32,1-14.

Choudhury, B.J., Dorman, T.J., Hsu, A.Y., 1995. Modeled and observed relations between the AVHRR split window temperature difference and atmospheric precipitable water over land surfaces. Remote Sensing of Environment 51, 281290.

Cresswell, M.P., Morse, A.P., Thomson, M.C., Connor, S.J., 1999. Estimating surface air temperatures from Meteosat land surface temperatures using an empirical solar zenith angle model. Inter national Journal of Remote Sensing 20, 1125-1132.

Cristobal, J., Ninyerola, M., Pons, X., 2008. Modeling air temperature through a combination of remote sensing and GIS data. Journal of Geophysical Research Atmospheres 113. D13106, doi:10.1029/2007JD009318.

Czajkowski, K.P., Goward, S.N., Stadler, S.J., Walz, A., 2000. Ther mal remote sensing of near surface environmental variables: application over the Oklahoma Mesonet. Professional Geographer 52, 345-357.

Dennison, P.E., Roberts, D.A., Peterson, S.H., Rechel, J., 2005. Use of normalized difference water index for monitoring live fuel moisture. International Journal of Remote Sensing 26, 1035-1042.

Dimitrakopoulos, A., Papaioannou, K.K., 2001. Flammability assessment of Mediterranean forest fuels. Fire Technology 37, 143-152.

EUMETSAT, 2007. Cloud Detection for MSG - Algorithm Theoretical Basis Document. Technical Report EUM/MET/REP/07/0132. EUMETSAT. Darmstadt, Germany.

Fensholt, R., Sandholt, I., 2003. Derivation of a shortwave infrared water stress index from MODIS near- and shortwave infrared data in a semiarid environment. Remote Sensing of Environment 87, 111-121.

Friedl, M.A., McIver, D.K., Hodges, J.C.F., Zhang, X.Y., Muchoney, D., Strahler, A.H., Woodcock, C.E., Gopal, S., Schneider, A., Cooper, A., Baccini, A., Gao, F., Schaaf, C., 2002. Global land cover mapping from MODIS: algorithms and early results. Remote Sensing of Environment 83, 287-302.

Garcia, M., Chuvieco, E., Nieto, H., Aguado, I., 2008. Combining AVHRR and meteorological data for estimating live fuel moisture content. Remote Sensing of Environment 112, 3618-3627.

Goward, S.N., Waring, R.H., Dye, D.G., Yang, J.L., 1994. Ecological remote-sensing at OTTER: satellite macroscale observations. Ecological Applications 4, 322-343.

Hao, X., Qu, J.J., 2007. Retrieval of real-time live fuel moisture content using MODIS measurements. Remote Sensing of Environment 108, 130-137.

Jang, J.D., Viau, A.A., Anctil, F., 2004. Neural network estimation of air temperatures from AVHRR data. International Journal of Remote Sensing 25, 4541-4554.

Jedlovec, G.J., 1990. Precipitable water estimation from high resolution split window radiance measurements. Journal of Applied Meteorology 29, 863-877.

Kleespies, T.J., McMillin, L.M., 1990. Retrieval of precipitable water from observations in the split window over varying surface temperatures. Journal of Applied Meteorology 29, 851-862.

Li, Z.L., Jia, L., Su, Z.B., Wan, Z.M., Zhang, R.H., 2003. A new approach for retrieving precipitable water from ATSR2 split-window channel data over land area. International Journal of Remote Sensing 24, 5095-5117.

Murray, F.W., 1967. On the computation of saturation vapor pressure. Journal of Applied Meteorology 6, 203-204.
Nelson, R.M., 1984. A method for describing equilibrium moisture content of forest fuels. Canadian Journal of Forest Research-Revue Canadienne De Recherche Forestiere 14, 597-600.

Nemani, R.R., Running, J.W., 1989. Estimation of regional surface resistance to evapotranspiration from NDVI and thermal-IRAVHRR data. Journal of Applied Meteorology 28, 276-284.

Nieto, H., Sandholt, I., Aguado, I., Chuvieco, E., Stisen, S. Air temperature estimation with MSG-SEVIRI data: calibration and validation of the TVX algorithm for the Iberian Peninsula. Remote Sensing of Environment, submitted for publication.

Pineiro, G., Perelman, S., Guerschman, J.P., Paruelo, J.M., 2008. How to evaluate models: observed vs. predicted or predicted vs. observed? Ecological Modelling 216, 316-322.

Prihodko, L., Goward, S.N., 1997. Estimation of air temperature from remotely sensed surface observations. Remote Sensing of Environment 60, 335-346.

Prince, S.D., Goetz, S.J., Dubayah, R.O., Czajkowski, K.P., Thawley, M., 1998. Inference of surface and air temperature, atmospheric precipitable water and vapor pressure deficit using advanced very high-resolution radiometer satellite observations: comparison with field observations. Journal of Hydrology 213, 230-249.

Rahman, H., Dedieu, G., 1994. SMAC-a simplified method for the atmospheric correction of satellite measurements in the solar spectrum. International Journal of Remote Sensing 15, 123-143.

Reitan, C.H., 1963. Surface dew point and water vapor aloft. Journal of Applied Meteorology 2, 776-779.

Rothermel, R.C., 1972. A Mathematical Model for Predicting Fire Spread in Wildland Fuels. Technical Report. USDA, Forest Service. Ogden, Utah.

Rouse, J.W., Haas, R.W., Schell, J.A., Deering, D.H., Harlan, J.C., 1974. Monitoring the vernal advancement and retrogradation (Greenwave effect) of natural vegetation. Type II Report for the Period April 1973 - September 1973. Goddard Space Flight Center. Greenbelt, MD. USA.

Ruiz Gonzalez, A.D., Vega Hidalgo, J.A., Alvarez Gonzalez, J.G., 2009. Construction of empirical models for predicting Pinus sp. dead fine fuel moisture in NW Spain. I: response to changes in temperature and relative humidity. International Journal of Wildland Fire 18, 71-83.

Schmetz, J., Pili, P., Tjemkes, S., Just, D., Kerkmann, J., Rota, S., Ratier, A., 2002. An introduction to Meteosat Second Generation (MSG). Bulletin of the American Meteorological Society 83, 977-992.

Schroedter-Homscheidt, M., Drews, A., Heise, S., 2008. Total water vapor column retrieval from MSG-SEVIRI split window measurements exploiting the daily cycle of land surface temperatures. Remote Sensing of Environment 112, 249-258.

Schwarz, F.K., 1968. Comments on note on the relationship between total precipitable water and surface dew point. Journal of Applied Meteorology 7, 509-510.

Simard, A., 1968. The moisture content of forest fuels-a review of the basic concepts. Technical Report. USDA, Forest Service. Ottawa, Ontario.

Smith, E.P., Rose, K.A., 1995. Model goodness-of-fit analysis using regression and related techniques. Ecological Modelling 77, 49-64.

Smith, W.L., 1966. Note on the relationship between total precipitable water and surface dew point. Journal of Applied Meteorology 5, 726-727.

Sobrino, J.A., Romaguera, M., 2004. Land surface temperature retrieval fromMSG1SEVIRI data. Remote Sensing of Environment 92, 247-254.

Sobrino, J.A., Romaguera, M., 2008. Water-vapour retrieval from Meteosat 8/SEVIRI observations. International Journal of Remote Sensing 29, 741-754.

Stisen, S., Sandholt, I., Norgaard, A., Fensholt, R., Eklundh, L, 2007. Estimation of diurnal air temperature using MSG SEVIRI data in West Africa. Remote Sensing of Environment 110, 262-274.

Suggs, R.J., Jedlovec, G.J., Guillory, A.R., 1998. Retrieval of geo physical parameters from GOES: evaluation of a split-window technique. Journal of Applied Meteorology $37,1205-1227$.

Tetens, O., 1930. Uber einige meteorologische Begriffe. Zeitchrift fur Geophysik 6 297-309.

Van Wagner, C.E., 1972. Equilibrium moisture contents of some fine forest fuels in eastern Canada. Technical Report. Canadian Forest Service. Chalk River, Ontario.

Van Wagner, C.E., 1987. Development and structure of the Canadian Forest Fire Weather Index System. Technical Report. Canadian Forest Service. Otawa.

VanWagner, C.E., Pickett, T.L., 1985. Equations and FORTRAN pro gram for the Canadian Forest Fire Weather Index System. Technical Report. Canadian Fores Service. Ottawa.

Viney, N.R., 1991. A review of fine fuel moisture modelling. International Journal of Wildland Fire 1, 215-234.

Viney, N.R., Catchpole, E.A., 1991. Estimating fuel moisture response times from field observations. International Journal of Wildland Fire 1, 211-214.

Viswanadham, Y., 1981. The relationship between total precipitable water and surface dew point. Journal of Applied Meteorology 20, 3-8.

Vogt, J.V., Viau, A.A., Paquet, F., 1997. Mapping regional air temper ature fields using satellite-derived surface skin temperatures. International Journal of Climatology 17, 1559-1579.

Willmott, C.J., 1982. Some comments on the evaluation of model performance. Bulletin of the American Meteorological Society 63, 1309-1313.

Willmott, C.J., Matsuura, K., 2005. Advantages of the mean absolute error (MAE) over the root mean square error (RMSE) in assessing average model performance. Climate Research 30, 79-82.

Yebra, M., Chuvieco, E., Riano, D., 2008. Estimation of live fuel moisture content from MODIS images for fire risk assessment. Agricultural and Forest Meteorology 148 523-536. 